\title{
Juarez Távora e a organização do estado Brasileiro: racionalismo administrativo, sindicalismo-cooperativista e cristianismo social no pensamento militar pré-golpe de 1964
}

\author{
Juarez Távora and the organization of the Brazilian state: \\ administrative rationalism, co-op unionism and social christianity in \\ military thought - pre-coup of 1964
}

Luiz Felipe Cezar Mundim*

RESUMO

\begin{abstract}
A Escola Superior de Guerra (ESG) no momento da sua criação, ao final da década de 1940, deu início à sua atividade de produção ideológica inserida em um campo cultural específico. A proposta teóricoadministrativa de Juarez Távora, um dos principais membros e comandante da Escola nos anos de 1953 e 1954, contribuiu para a construção de um projeto de nação a ser apresentado pela ESG. Este artigo procura destacar da obra, e da trajetória política de Juarez Távora, alguns dos principais elementos dessa proposta, tais como a defesa da racionalização administrativa e as ideias de Sindicalismo-Cooperativista e Cristianismo Social.
\end{abstract}

Palavras-chave: Escola Superior de Guerra. Estado. Intelectuais. Doutrina de Segurança Nacional.

\footnotetext{
* - Doutorando em História pela Universidade Federal do Rio Grande do Sul. Mestre em História pela Universidade Federal de Goiás (2007). Bacharel e licenciado em História pela Universidade Federal de Goiás (2003), e bacharel em Relações Internacionais pela Pontifícia Universidade Católica de Goiás (2003). Formação com ênfase na área de História Contemporânea e História do Brasil República, atuando principalmente com os seguintes temas: história social do trabalho, história intelectual, história dos militares e história de organizações de público.
} 


\section{ABSTRACT}

The National War College in Brazil (ESG) at the time of its creation, in the end of the 1940s, began the vity of ideological production inserted in a specific cultural field. The theoretical and administrative posal of Juarez Távora, one of the most important member and commander of the institution in 1953 and 4 , contributed to construct a national project to be presented by ESG. This paper seeks to highlight within work, and by the political trajectory of Távora, some of the main elements of this proposal, such as the ense of administrative rationalization and the ideas of Co-op Unionism and Social Christianity.

Keyword: ESG. State. Intellectuals. National Security Doctrine.

Juarez do Nascimento Fernandes Távora nasceu em Jaguaribemirim, atual Jaguaribe, em 14 de janeiro de 1898, na fazenda Embargo. As suas origens familiares eram de lutas oligárquicas contra os Acióli, que exerceram o domínio no Ceará durante a República Velha. Formou-se engenheiro e frequentou escolas como Pedro II no Rio de Janeiro, Júlio de Castilhos em Porto Alegre e o curso de Engenharia da Escola Politécnica do Rio ${ }^{1}$. Após essa formação - muito comum aos militares e civis preparados para dirigir o Brasil no início do Século XX -, Juarez Távora atravessou todo o século XX como um dos principais personagens na história política brasileira, embora apareça apenas de maneira secundária na historiografia. ${ }^{2}$

Como exemplo, de um lado, sempre que os estudos históricos se debruçam sobre as fontes acerca da coluna Miguel Costa-Prestes, sobre o movimento de 1930 e todo o tenentismo em sua acepção conceitual que the foi atribuída, a figura de Távora é constante como personagem decisivo. A ele foi conferido um dos principais papéis na incursão dos militares revoltosos na década de 1920 , desde o primeiro cinco de julho, o de 1922, e em todos os movimentos que se seguiram contra o governo, até a vitória da Revolução de 1930. E de outro lado, entretanto, a sua trajetória representada na historiografia sobre as décadas de 1930, 1940 e 1950 é observada como repositório automático do ideário tenentista; e que nada mais, além desse ideário, seria herdado pela Escola Superior de Guerra (ESG), onde Távora contribuiu de maneira decisiva como ideólogo da Doutrina de Segurança Nacional (DSN) por meio do posto de comandante nos anos de 1953 e 1954.

Ainda hoje falta a esse personagem análise mais detida do conjunto da sua obra bibliográfica. Proponho contribuir com essa tarefa que deve, além de observar as ideias que motivaram a sua trajetória política, buscar a dinâmica da relação dessa trajetória com o meio institucional em que

1 Para esses dados iniciais da biografia de Juarez Távora, ver o primeiro volume de suas Memórias (1974, caps. I e II). 2 Dentre as principais obras em que Juarez Távora aparece com alguma notoriedade nas análises, destaca-se: Vavy Pacheco Borges (1992), José Murilo de Carvalho (2005); Eduardo Munhoz Svartman (2006, p. 82-90, 120-142 e 170206); Maria Cecília Forjaz (1977); Edgard Carone (1976), na primeira parte, letras F, N, O e toda a segunda e a terceira parte do livro. 
Távora produzia e reproduzia as suas ideias, e a evolução das suas posições e opções. O período entre 1924 e 1964 na realidade militar brasileira deve ser observado com cuidado, e o percurso de Juarez Távora pode ser uma janela para visualizar alguns elementos singulares sobre a evolução do pensamento militar que culminaram com a ditadura civil-militar.

Essa preocupação torna-se latente no simples contato com certos pormenores na obra do militar, pois, abrem o questionamento sobre a ligação mecânica de suas ideias apenas ao ideário militar. O que este artigo coloca em perspectiva é que: muito embora o espírito corporativo estivesse presente na atuação político-militar de Távora, ao se observar a evolução da sua obra torna-se insustentável a ligação automática entre as suas idéias e, somente, a sua posição militar; e que é necessário apontar elementos na composição da DSN que, em muito, extrapolavam a motivação organizacional do Exército e das outras Armas pela simples adequação ao concerto internacional bipolarizado. Com a intenção de propor certa abertura nessa leitura, pretendo localizar em alguns pontos da obra, e da trajetória política de Távora, os traços gerais do projeto político que carregou durante a sua carreira militar e pública e, assim, identificar traços da relação desse projeto com a organização do Estado brasileiro.

Távora escreve como se fizesse relatórios temáticos e manuais técnicos. Não há qualquer tentativa mais apurada de interpretação histórica e filosófica do Brasil, a não ser esparsamente em algumas das suas palestras, mas sempre de maneira tímida, ao contrário, por exemplo, do Golbery do Couto e Silva, que se lança francamente sobre a filosofia da história para elaborar sua própria ideia de história do Brasil. Em contrapartida, no conjunto dos seus escritos, que formam material textual relativamente extenso, é possível tornar visível o projeto de organização para o Brasil e, nele, a reunião de alguns dos principais traços da visão de mundo desenvolvida na ESG, no final da década de 1940 e de toda a década de 1950. Esse projeto viria a contribuir, em conjunto com a obra de Golbery do Couto e Silva, para a elaboração do chamado Conceito Estratégico Nacional da escola e, por fim, para a Doutrina de Segurança Nacional, bases ideológicas do golpe de 1964 .

Nesse percurso político-militar de Távora, foi impresso o caráter peremptório do sentido racionalista e tecnoburocrático para a organização do Brasil. A exposição acompanhará um pouco desse percurso, enfatizando os conteúdos dos livros e dos escritos publicados por Távora nesse sentido. Entretanto, como não se trata de autor com trabalho intelectual regular e de produção textual característica do ideólogo e técnico do conhecimento, a análise não se restringe aos aspectos estritamente internos dos textos. Busca, também, somar a perspectiva relacional dos elementos históricos indissociáveis às publicações dos livros.

Disponho a análise, portanto, em dois itens que orientam essa abordagem: no primeiro, apresento o autor no papel de personagem, tendo em vista o percurso inicial da sua luta diante do diagnóstico de desorganização do Brasil, com ênfase nas ideias para a Revolução, encontradas no seu primeiro livro, À Guisa de depoimento, em que sintetizou os fundamentos do pensamento autoritário e intervencionista dos militares brasileiros a partir de 1924; no segundo item, apresento o Távora que se firma enquanto ideólogo, dispondo as principais ideias da sua obra, buscando 
demonstrar o sentido da proposta de um Brasil estritamente organizado nas bases do sindicalismocooperativista e do cristianismo social, categorias centrais para a sua proposta de uma organização do estado brasileiro com base na racionalização da administração e da produção, e numa harmonia social conservadora.

\section{A incorrigível realidade brasileira: eterna luta frente ao diagnóstico de desorganização do Brasil}

Dividida em três volumes, a obra Uma vida e muitas lutas - Memórias é um valioso documento histórico sobre o Brasil do século XX. Távora depõe de maneira diferente comparado a outros militares, como Cordeiro de Farias ou Geisel, e organiza uma estrutura narrativa memorial, buscando descrever os fatos sob a marca assertiva do "tal como foram vistos e vividos", com a preocupação em sustentar a narrativa a partir da reunião de vários documentos; o depoimento, assim, além de ser mais individualizado e subjetivo, é também preciso em relação a certos dados, o que constitui interessante fonte de pesquisa. As Memórias não constituem, aqui, a principal fonte, de maneira que as utilizei mais para orientação histórico-institucional da vida de Juarez Távora, na medida em que apresento o restante de seus livros.

Acompanhando a narrativa de Távora sabemos que, por sugestão do primo, então tenente do Exército servindo no Rio, os irmãos Juarez Távora e Fernando Távora ingressam a Escola Militar do Realengo (CARVALHO, 2005, p. 24-28) em 1916, onde poderiam estudar custeados pelo governo federal e sem maiores impedimentos de admissão, por já estarem cursando a Escola Politécnica.

Antiga Escola Militar da Praia Vermelha, de 1858, que havia sido fechada em 1904, a Escola Militar no Rio de Janeiro ficou marcada durante a segunda metade do século XIX pelo caráter positivista do ensino, em detrimento da função militar da Escola, sobretudo após o ingresso de Benjamim Constant no quadro docente em 1972. No início do século XX, com a reabertura no ano de 1911 em Realengo, a influência predominante seria do hermismo, com a ênfase da formação voltada a modernizar Exército. O período foi caracterizado pela atuação dos chamados Jovens Turcos, oficiais que mantiveram contato com a organização militar alemã no começo do século, da qual Hermes da Fonseca era entusiasta, e que precedeu a visita da Missão Francesa ao Brasil. Criaram a famosa revista militar A Defesa Nacional, onde difundiram o sistema de treinamento especializado, o patriotismo e a luta por medidas como o sorteio, a educação militar, o afastamento da política e a defesa nacional.

Juarez Távora se formou nesse ambiente, em que a instrução das várias Armas recebeu a "tônica de objetividade e renovação que ela nunca dantes tivera". (TÁVORA, 1974, p. 94) A 
descrição da rotina da Escola Militar feita por Távora ilustra bem a absorção da disciplina e a estrita obediência à hierarquia, elementos fundamentais da reforma que visava profissionalizar a carreira militar e que inaugurava nova fase da formação dos quadros de oficiais das Forças Armadas através das escolas e colégios militares.

\section{1- A experiência do tenentismo e a primeira visão de um Brasil desorganizado}

Távora participou do plano revolucionário de cinco de julho de 1922, na Escola Militar do Realengo. Seguindo sempre os caminhos do irmão Joaquim Távora, logo aderiu às lutas empreendidas pelos revoltosos que ficaram conhecidos como tenentes, não demorando assumir importante papel de liderança, principalmente ideológica, do movimento.

O primeiro levante desencadeou-se pelo descontentamento de parte dos oficiais do Exército, principalmente de baixo-patente e ligados a Hermes da Fonseca, com o episódio das três cartas falsas atribuídas a Artur Bernardes. Uma delas, publicada em nove de novembro de 1921, na primeira página do Correio da Manhã, em plena campanha presidencial em que disputavam o suposto autor e Nilo Peçanha, teria insultado a oficialidade do Exército.

Desencadeada a crise político-militar que, num primeiro momento, foi protagonizada pelo Clube Militar, na figura de Hermes da Fonseca, e pelo presidente Epitácio Pessoa, que se posicionou ao lado do candidato vencedor, Artur Bernardes, a questão se estendeu por todo o primeiro semestre de 1922, resultando na prisão de Hermes da Fonseca em $1^{\circ}$ de julho daquele ano.

Na visão de Távora, assim como na da maioria dos demais oficiais envolvidos no levante de 1922, as motivações da revolta tiveram as suas origens tão-somente no espírito corporativo do Exército, que teria sido seriamente ofendido pelos políticos no poder, e "não visava - pelo menos até o momento de ser desencadeada - senão depor uma autoridade constituída - o Sr. Epitácio Pessoa e impedir, talvez, a posse da autoridade constituenda do Sr. Arthur Bernardes". A questão, que não teria ultrapassado os limites pessoais, teria de ainda assim abalado o orgulho militar: "a centelha de revolta, então inexplicavelmente abafada, longe de extinguir, agravara, ainda mais, o mal-estar soturno que lavrava no seio do exército nacional”. (TÁVORA, 1928, p. 143-144).

Em suas memórias, escritas muitos anos mais tarde, Távora mantém a mesma opinião: "participei, ativa e conscientemente, do levante militar de 5 de julho de 1922, feito como protesto contra os atos do Presidente Epitácio Pessoa, que considerava ofensivos à dignidade do Exército." (TÁVORA: 1974, p. 115). 
Segundo J. M. de Carvalho, a natureza de esprit de corps desse levante, que chama de Segundo Tenentismo (o primeiro teria sido o movimento de proclamação da República), teve pouco respaldo na totalidade do Exército e menos ainda nas outras Armas, motivando apenas parte de jovens oficiais e parentes de Hermes da Fonseca. Formavam a parcela do Exército que se revoltou, apenas, a Escola Militar do Realengo - onde a influência dos Jovens Turcos havia sido decisiva nos últimos dez anos para incutir nos jovens cadetes o caráter profissionalizante e corporativo -, o Forte Copacabana no Rio de Janeiro, e a guarnição local de Mato Grosso - que, tal como o Forte, era comandado por parentes do Marechal Hermes. (CARVALHO, 2005, p. 49) ${ }^{3}$.

Preso logo no primeiro dia de levante, Távora permaneceu três meses preso na ilha das Cobras, onde teve o seu primeiro e decisivo contato com a obra de Alberto Torres. ${ }^{4}$ Após mudar de prisão duas vezes e ser promovido ao posto de capitão em 14 de novembro, um dia antes de Artur Bernardes assumir, permaneceu encarcerado até fevereiro de 1923, quando os prisioneiros do levante receberam habeas corpus do Supremo Tribunal Federal. Passou, então, a morar em quarto de pensão com Artur da Costa e Silva. Ao tomar conhecimento de que recebera a pena máxima do Código Penal Militar - três anos de reclusão, perda da patente e exclusão automática do Exército -, desertou e aderiu à conspiração que preparava o levante de 1924. (TÁVORA, 1974, p. 111-136).

Atuando no Paraná e no Rio Grande do Sul, articulou com Luís Carlos Prestes, Osvaldo Cordeiro de Farias, o seu irmão Joaquim e o principal líder, Isidoro Dias Lopes, e assumiu importante papel no aliciamento e na disseminação das idéias do movimento que se preparava.

Em 1925, acompanhou a marcha da Coluna batizada Miguel Costa-Prestes, mas foi preso no último dia do mesmo ano às margens do Parnaíba, quando a Coluna preparava a investida sobre Piauí. Com outros revoltosos, como Eduardo Gomes e Carlos Chevalier, foi enviado para a ilha de Trindade no Espírito Santo. Durante o tempo em que permaneceu preso na ilha, releu as suas coleções de Alberto Torres e Euclides da Cunha. Escreveu, então, as suas notas e as suas impressões do movimento de 1924, que seriam publicadas mais tarde. Após a posse de Washington Luís, os presos foram enviados à ilha das Cobras, já no Rio. Com a suspensão do estado de sítio, Távora pôde publicar parcialmente os escritos que vinha elaborando. A convite de Nereu Pestana d'O Combate, publicou em 1927 o primeiro volume de seu À guisa de depoimento sobre a revolução brasileira de 1924, obra de memórias da experiência com o levante de 1924 e com a coluna.

O livro deveria se organizar em três volumes, sendo que o primeiro trataria do levante de 1924; o segundo, da retirada de São Paulo e do início das atividades da marcha; o terceiro, do restante da

3 Ver também Carone (1976, p. 30-43) e Scalércio (1995, p. 56).

4 Alberto Torres, nascido em Itaboraí (RJ) em 1865, político e ideólogo do começo do século XX, ficou conhecido por suas críticas em relação à configuração política do Brasil e da "pretensão democrática" que, a seu ver, eram inúteis e inadequadas: "Somos um país sem direção política e sem orientação social e econômica. [...] O patriotismo sem bússola, a ciência sem síntese, as letras sem ideal, a economia sem solidariedade, as finanças sem continuidade, a educação sem sistema, o trabalho e a produção sem harmonia e sem apoio [...]." (TORRES: 1914, p. 17). Em O Problema Nacional, Torres foi enfático quanto à necessidade da "restauração conservadora e reorganizadora", em que seria papel das "elites" o de reorganizar o País politicamente e assumir a direção da nação. Seria fundamental, segundo Torres, estabelecer um governo e uma organização política que prezasse pelo centralismo, abrindo mão da democracia. (TORRES, 1982, p. 133). 
campanha da coluna ${ }^{5}$ e, principalmente, das idéias que motivavam o combate, realizando o primeiro diagnóstico do que Juarez Távora via como desorganização do Brasil e da sua expectativa com a posse do presidente Washington Luís.

São lançados apenas o primeiro e o terceiro volumes, sendo o terceiro no Rio de Janeiro em 1928, pela Mendonça Machado e Cia. Távora diz, em nota aos dados bibliográficos das suas Memórias, que a não publicação do segundo volume se deveu à invasão que sofrera na casa por policiais do governo em janeiro de 1930, após ter sido preso. Os policiais teriam desorganizado todo o material do segundo volume, além de destruir uma parte, desmotivando-o de reorganizá-lo novamente. ${ }^{6}$

Da sua fuga em 1927 para Montevidéu, onde estabeleceu novo contato com Isidoro Dias Lopes para tratarem da preparação de mais um movimento armado, passando pelo período em que morou em uma república com Siqueira Campos e João Alberto e o exílio em Buenos Aires em 1929, as atividades conspiratórias continuaram e se intensificaram. As motivações tornaram-se, também, sociais e econômicas, além de políticas e militares, devido ao contato que a Coluna estabelecera com a realidade do sertão brasileiro. Foi devido a esse contato, além daquele com a literatura marxista, que Prestes foi levado a se desmembrar do grupo que liderava as conspirações, criticando o diálogo com a Aliança Liberal e voltando-se francamente ao comunismo. ${ }^{7}$

Desse desentendimento, produziu-se uma série de importantes documentos, como o manifesto de Prestes e as cartas de Juarez Távora, polemizando e debatendo as questões levantadas pelo manifesto. A polêmica marcou o ponto decisivo, no Brasil, de disputa ideológica que se estenderia por quase todo o restante do século e que seria objeto de grande parte das preocupações de Juarez Távora e, por fim, da ESG.

Nas cartas trocadas com Prestes, prevalece no discurso de Távora a defesa da harmonia social, da autoridade e da neutralidade do Estado e da administração pública, orientados por uma vocação que fosse própria e natural ao Brasil, lembrando Alberto Torres. Em réplica ao manifesto de Prestes, Távora diz crer "no equilíbrio e excelência de um regime baseado na representação proporcional de todas as classes sociais, e erigido em regulador imparcial de suas dependências e interesses recíprocos" e que mesmo sendo o regime republicano democrático o que mais facilmente poderia permitir a aproximação a esse equilíbrio ideal, esse regime deveria ser adaptado às "nossas realidades". (TÁVORA, 1974, p. 353).

E apresenta a sua perspectiva para a revolução:

5 Como Juarez Távora havia sido preso ainda no final de 1925, e a Coluna continuava em atividade no ano seguinte, a descrição do restante da campanha se deveu, principalmente, à contribuição de Lourenço Moreira Lima, que cedeu a Távora o seu diário de campanha e de informações com detalhes dos momentos finais da marcha. Ver CPDOC-FGV JT dpf 1924.05.10.

6 Ver nota da p. XI do segundo volume das Memórias. (TÁVORA, 1974-1976, p. xii).

7 Ver o relato pessoal de Távora (1974-1976, p. 6-7) para este momento. 
O fortalecimento da liberdade civil, por uma reforma criteriosa da Justiça; o estabelecimento da independência econômica das massas, pela difusão da pequena propriedade; a coibição efetiva e prática dos arbítrios do poder, pela criação de um novo organismo de controle político; o equilíbrio social, estabelecido pela proporcional representação de classe; e, enfim, a continuidade indispensável à obra de solução dos grandes problemas nacionais, pela influência persistente de conselhos técnicos, que se superponham, permanentemente, à temporariedade dos governos - eis os pontos básicos por que se devem bater, vencidos ou vencedores, os revolucionários brasileiros. (TÁVORA, 1974, p. 353).

Juarez Távora iniciava a sua espécie de cruzada, por todo o restante da carreira, pela organização segura e harmônica do Brasil, livre da influência de "doutrinas exóticas", principalmente a que começava a "ameaçar seriamente" o Brasil: o comunismo.

\section{2.- Os militares e a Revolução em À guisa de depoimento}

O período histórico que compreendeu a Revolução de 1930, certamente um dos mais debatidos na historiografia do Brasil contemporâneo, compreende vários estudos sobre o tenentismo e a sua ideologia, como movimento fundamental na dinâmica de conflitos e disputas políticas e ideológicas mais amplas. ${ }^{8}$ Sobre o tenentismo, como movimento dotado de esboço político mais bem traçado, o debate em torno da sua ideologia provavelmente iniciou-se em 1927, quando Juarez Távora publicou À guisa de depoimento. ${ }^{9}$ Poucos anos mais tarde, Virgínio Santa Rosa empreendeu a primeira tentativa de "caracterização sociológica" do movimento, ligando-o à atuação da classe média. (SANTA ROSA, 1976). Décadas mais tarde, tendo o uso da categoria já sido consagrado, o debate foi encampado pela academia nos termos de discussão sobre a natureza do movimento, se de classe média ou se de origem corporativa - estritamente militar.

Para além das duas possíveis naturezas do movimento, no depoimento de Juarez Távora porta-voz do grupo que passaria a ser denominado como dos tenentes apenas após o sucesso da Revolução - já pode ser percebido de maneira latente o sentimento de reprovação do modelo político vigente na década de 1920. O discurso denotava pouca crença nos políticos daquela época,

8 Para um estudo do tenentismo como movimento político, ver: Svartman (2006, p. 126-127). Ver, também, além do trabalho citado de Svartman e Vavy Pacheco Borges (1992), Edgard Carone (1976), Boris Fausto (1975), Maria Cecília Spina Forjaz (1977, 1978), Otávio Malta (1969), Virgínio Santa Rosa (1976, original em 1933) e Hélio Silva (1967, 1968). E para o conflito entre os tenentes e as oligarquias ver a obra citada de Vavy Pacheco Borges (1992, cap. 4 e 5).

9 Afirmação originalmente de Svartman (2006, p. 87). 
e a perspectiva de que no grupo militar nele representado estaria uma espécie de reserva não apenas moral da nação, mas, também, a qualidade de único competente para incutir no Estado a mais correta e racional organização político-administrativa.

À guisa de depoimento, literariamente, compunha estilo que se aproximava com devoção de Alberto Torres. A reprovação do modelo político seguia, na mesma medida, o ímpeto de Torres. Após seis anos de combates e fugas, quase sempre justificadas apenas no espírito corporativo, o movimento ganhava visão política clara para a sua atuação. A sua ideologia se desenvolveu em conformidade com a sua evolução como grupo militar sedicioso, que dependia do aliciamento de adeptos e, principalmente, do contato estabelecido com a realidade econômica e social do Brasil durante a marcha da Coluna.

A noção de deslocamento do modelo político adotado pelo Estado brasileiro se inspirava nos apontamentos de Alberto Torres e na ênfase deste autor no caráter exótico do modelo liberal para a república brasileira. No livro, Juarez atribui os problemas do sistema à inadaptabilidade e à incapacidade política de adotar o liberalismo:

Como terá podido degenerar, em tal monstruosidade, o mecanismo
teoricamente liberal e democrático, de nossa constituição? Será isso um
atestado da incapacidade política da raça - ou um sintoma de
inadaptabilidade do complexo sistema adotado, às tendências do povo? É,
talvez, o resultado da atuação conjunta desses dois fatores. (TÁVORA, 1928,
p. 148-149).

Ao problema da degeneração do modelo político adotado pela república brasileira se corelacionava o da má-formação da elite governamental nos pendores liberais, abrindo espaço para adesistas de última hora que se interessavam apenas pelo lugar seguro do poder:

[...] Se, ao menos, a maioria dos tangedores de rebanhos políticos fosse capaz de dirigir, com critério e independência, a atuação do seu eleitorado, o mal seria praticamente diminuto, ou não existiria. Mas esses pastores singulares - constituídos pelos nossos sertanejos - geralmente ingênuos ou atrasados - deixam-se conduzir [...] ao sabor das conveniências, dos "azes" das agremiações partidárias, a que pertencem. Constituem estes magnatas a nossa elite dirigente e são, de fato, os responsáveis diretos de todas as nossas mazelas políticas. [...] Carecem, entretanto, de educação moral, de critério, de independência e, sobretudo, de verdadeiro patriotismo, para 
colocarem, acima dos interesses pessoais, as médias aspirações de bem estar da coletividade. Eles, que, pela sua cultura, deveriam guiar, com ponderação e eqüidade, a turba submissa dos ignorantes, falseiam, deploravelmente, essa missão, destilando, sobre a ingenuidade do eleitorado sertanejo, o veneno da mesma fatalidade que os tem feito, sempre, joguetes de paixões mesquinhas e de interesses baixos ou inconfessáveis. (TÁVORA, 1928, p. 208-209).

Tal grupo, "de atuação negativa e criminosa" e que representaria "a página mais infame da nossa degenerescência democrática" segundo Távora, não poderia representar a verdadeira elite governamental do País. (TÁVORA, 1928, p. 151-153) Era devido a essa "degenerescência" da década de 1920 representada pelos mandos e desmandos do poder executivo, principalmente pelo governo de Artur Bernardes quase todo sob estado de sítio, que, para Juarez Távora, deveu-se a reação dos militares do movimento de 1924.

A partir desse primeiro diagnóstico esboçou-se, também, programa político que compreendia medidas apenas reformistas, de caráter jurídico-político, em relação à Constituição de 1891. Essas medidas, dispostas primeiramente no terceiro volume de $\grave{A}$ guisa de depoimento, apareceriam novamente cinco anos depois, com poucas mudanças, nas sugestões de reformas a serem realizadas pela Ditadura, no relatório da viagem de Távora ao Norte-Nordeste encomendada por Getúlio Vargas, e no programa do Clube 3 de Outubro. ${ }^{10}$

O caráter liberal-democrático que o programa sugeria defrontava-se, entretanto, com a terminologia usada para definir o próprio povo. Percebe-se que, segundo Távora, os "revolucionários" conferiam a eles mesmos, e não à sociedade, a exclusividade no protagonismo do processo de mudança política. Conforme Svartman aponta, Juarez Távora havia deixado explícita essa idéia quando definiu os papéis e a legitimidade da ação dos atores envolvidos no processo político em curso ainda no primeiro volume de À guisa de depoimento:

Quando o governo está com a lei, a força armada deve apoiá-lo, ainda que haja de combater o próprio povo. Quando, porém, os governos mutilam a lei e desrespeitam a Constituição, compete à força armada colocar-se ao lado destas, ainda que seja mister destruir, provisoriamente, o poder constituído. É uma leviandade afirmar que, em tal hipótese, cabe ao povo e não à força armada derrubar o governo que a tiraniza. A massa imbele da nação dificilmente poderá vencer, sozinha, a guarda pretoriana que defende

10 Ver a descrição das medidas em Juarez Távora (1928, p. 156-161, p. 181-183). Ver também os pormenores de cada reforma nos capítulos VII, VIII, IX e X. 
déspotas. [...]. E essa interferência benéfica da força armada não se tem limitado apenas a permitir ao povo descartar-se de seus tiranos: tem valido, no meio das desordens generalizadas que caracterizam essas crises sociais, um escudo protetor da nação contra os excessos da indisciplina popular. (TÁVORA, 1927, p. 90) ${ }^{11}$

Juarez Távora, naquele momento, reservava aos militares o papel de guardiões da nação, responsáveis pela reforma dentro da ordem, quando fosse necessária, e por garantir o impedimento da mobilização popular. Para essa fração dos tenentes que, de volta ao Exército após a vitória de 1930, mas que não abandonou a carreira política, o sentido da luta foi construído pelo reforço do voluntarismo reformista "pelo alto", fixado na autocrença da opção mais racional e, assim, na crítica antioligárquica, que vinha desde os tempos do Realengo. (SVARTMAN, 2006, p. 133).

Além desse elemento conservador e elitista, o processo também tem a marca definitiva do autoritarismo. Muito embora o movimento devesse ser apenas reformista, para Távora, ele não perderia o seu caráter "revolucionário", principalmente quando se tratava de definir os aspectos políticos dos momentos iniciais da mudança a ser empreendida pela nova "elite". Tal mudança deveria, como é de praxe nos golpes políticos no capitalismo moderno, passar pelo momento que Juarez definia como instrumental à mudança "revolucionária", ou seja, pela ditadura:

A ditadura militar, que a procuradoria criminal da República deveria considerar, mais tarde, [...] como o objetivo político dos revolucionários, não foi prevista, em verdade, por alguns destes, senão como um instrumento transitório, indispensável à elaboração da reforma projetada. Dentro dos tramites constitucionais, descriam, avisadamente, de poder realizá-la, porque não seria possível eximi-la da interferência insidiosa dos conluios partidários. (TÁVORA, 1928, p. 160-161).

A crença no elitismo e na posição dos militares como vanguarda da Revolução permaneceria até o desencadeamento do movimento. Em junho de 1930, Juarez envia carta ao Tenente Joaquim Monteiro, encarregado pela chefia do movimento na Bahia, pontuando os seus pensamentos sobre o andamento das articulações "revolucionárias". Os pensamentos são permeados por preocupações com o apoio da Aliança Liberal e demais políticos da oposição, que não teriam idéias tão avançadas quanto às da "corrente revolucionária" formada "pela parte moça do Exército". Portanto, apesar de o grupo civil formar importante parceria para o sucesso da Revolução, esta deveria se encaminhar à

11 Citado também por Svartman (2006, p. 132). 
ditadura assim que lograsse sucesso, como forma de garantir as medidas previstas no programa de reformas dos militares.

Iniciado o movimento de 1930, Juarez Távora assumiu posição de liderança no NorteNordeste. As articulações com políticos da Aliança Liberal, como Osvaldo Aranha, Getúlio Vargas, Antônio Carlos e outros dissidentes do antigo regime, abriram-lhe o caminho da política institucional; a vitória permitiu que esse caminho fosse acessível tanto àqueles que desde 1922 haviam se insurgido, quanto aos da segunda "geração", que chegaram ao poder sem ter passado pela prisão e pelo exílio. (SVARTMAN, 2006, p. 133).

A Revolução de 1930 projetou o Exército para o centro do poder nacional, principalmente pela burocracia militar, estrutura organizacional que o novo sistema exigiria e que apenas o Exército possuía. Durante o restante da década e, principalmente com o Estado Novo, o Exército, por intermédio de Góes Monteiro e de Dutra, realizou uma série de reformas, tendendo a seu fortalecimento e a seu aparelhamento. Conforme J. M. de Carvalho indica, o Exército até então não possuía a hegemonia do poder de coerção na sociedade, pois enfrentava a concorrência das polícias estaduais. Com as reformas, o Exército fortaleceu a sua capacidade de ingerência sobre a política nacional e sobre as agendas de política externa, de infraestrutura e de defesa. (CARVALHO, 2005, p. 87-101).

Entretanto, a vitória se mostraria demasiadamente precária em seu pressuposto tenentista de racionalizar e organizar o Estado, tal qual Juarez Távora esperava das mudanças reformistas da revolução. Seria mais importante a preocupação com os destinos do País pela via de reformas institucionais mais amplas, tendo como principal objeto de anseio a reforma do Estado, do que os problemas estritamente corporativos do Exército. Távora distanciou-se, com isso, da visão da cúpula do Exército durante os anos que se seguiram, até a deposição de Vargas em 1945.

\section{2.-O Brasil organizado: espaços institucionais e reforma política}

Embora não estivesse próximo aos principais líderes militares com Vargas no poder, Juarez Távora percorreu caminho político-militar de destaque nesse período, desfrutando de uma abertura do meio político-institucional em que pôde trabalhar as suas idéias, que visavam mais à prática do que à reflexão. Mais tarde, esse trabalho o colocaria no quadro de controle das Forças Armadas e, também, nas posições mais altas do governo. Durante esse percurso, a sua experiência institucional refletiu-se em seus esforços de sintetizar as suas idéias para a organização do Brasil. 
Depois de À guisa de depoimento, publicou mais seis livros, sem contar as Memórias. Os livros são, todos, apanhados de textos, conferências e trabalhos realizados durante as décadas de $1930 \mathrm{e}$ 1940 e durante a sua passagem pela ESG. Com as conferências realizadas na ESG, organizou a maioria do conteúdo dos seus livros publicados pela Livraria José Olympio Editora, sendo cinco no total.

Távora reunia essas conferências de acordo com um tema em comum, mas nunca de forma totalmente coerente. Publicava os livros quase sempre sem atualizar os dados dos textos originais invariavelmente dizia, nas introduções dos livros, que não havia tempo para atualizá-los, mas que isso não prejudicava as idéias centrais. Em sua maioria, os textos aparentam ser manuais técnicos, seja pela estrutura formal, ao estilo das instruções militares, seja por meio de tópicos diretos e pragmáticos, fazendo sempre o movimento de apresentar o diagnóstico e a sua possível resolução.

Não há como apontar, incisivamente, outras grandes influências em sua obra do que a de Alberto Torres, que, por sua vez, era efusivamente citado nos livros. Muito raramente Juarez Távora fez referência ou citou algum outro autor. Entre esses momentos raros, aparecem Oliveira Vianna e Hitler. Távora, à sua maneira, procurou acrescentar elementos à obra de Alberto Torres, principalmente referentes à conformação ideológica das suas propostas. Neste ponto, buscou traduzir as idéias autoritárias de Torres para um sistema ideológico de orientação "econômica", o qual chamou de Cristianismo Social.

Quando assumiu a 20 subchefia do Estado-Maior do Exército em 1946, empenhou-se na discussão pública sobre a política de petróleo, pronunciando várias conferências entre maio de 1947 e junho de 1948, nos Clubes Militar e Naval, na ABI, no Rio, e no Instituto de Engenharia em São Paulo. Desse interesse e envolvimento direto com o debate sobre a política do petróleo, publicou o seu quarto livro em 1955, Petróleo para o Brasil, o primeiro editado pela José Olympio.

Lançou o seu terceiro livro pela José Olympio quase nas mesmas condições. Em agosto de 1955, quando foram realizados os acordos atômicos entre o Brasil e os EUA, Távora participou ativamente das negociações e, por isso, foi atacado pela oposição da sua candidatura à presidência da República, que o acusou de submissão aos interesses imperialistas. Dessa questão e da sua repercussão, publicou Átomos para o Brasil em 1958.

Naquele contexto, exonerou-se do cargo de chefe do Gabinete Militar do presidente Café Filho em abril de 1955, e lançou a sua candidatura em maio, empreendendo campanha que pregava idéias quanto à reforma eleitoral, como a adoção da cédula oficial e da eleição de um candidato apenas por maioria absoluta. A reforma foi amplamente debatida no Congresso em 1955, mas as teses foram refutadas para o pleito daquele ano. Foi dessa organização da sua campanha, do seu projeto de governo, que publicou Produção para o Brasil em 1957 e Organização para o Brasil em $1959 .{ }^{12}$

12 Doravante, respectivamente, Produção e Organização. 
O seu último livro, Uma Política de Desenvolvimento para o Brasil, de 1962, quinto publicado pela José Olympio, também foi escrito no contexto do seu envolvimento direto com a política, quando estava prestes a candidatar-se deputado federal pela Guanabara. Também composto por conferências proferidas isoladamente em 1959, 1960 e 1961, o livro marcou a saída de Távora da vida pública com o aparecimento da ênfase na política de educação, ponto que até então era recorrente na sua obra, mas não principal.

O primeiro livro que publicou após À guisa de depoimento surgiu do seu trabalho como ministro da Agricultura do governo provisório de Getúlio Vargas. O Ministro da Agricultura perante a Assembléia Nacional Constituinte, publicado em 1934, definiu os traços dos elementos centrais no seu pensamento, e que reapareceriam no restante dos seus livros: a racionalização administrativa, a produção, o sindicalismo-cooperativista e o cristianismo social.

\subsection{A racionalização administrativa}

Assim que o movimento de outubro de 1930 logrou êxito, Juarez Távora ocupou o cargo de chefe militar da Revolução do Norte e, mais tarde, o de delegado militar nas interventorias da região, cargo que assumiu em 12 de dezembro, passando a ser chamado pela imprensa de "ViceRei do Norte". Antes de aceitar o cargo de delegado, Getúlio o convidou para ocupar o cargo de ministro da Viação e Obras Públicas, o qual recusou, alegando o compromisso dos chefes militares de não ocupar postos na administração civil.

$\mathrm{Na}$ ocasião, disse que caberia às Forças Armadas, apenas, garantir ao governo a necessária segurança para que este realizasse a "obra de renovação revolucionária". No entanto, atendendo à solicitação de Osvaldo Aranha, que o alertara, dizendo que tal negação poderia ser interpretada como desentendimento entre os "revolucionários" do Norte e o novo governo, aceita e ocupa o cargo apenas de 4 a 24 de novembro, indicando depois José Américo de Almeida para assumir a pasta. (TÁVORA, 1974-1976, p. 11).

Após esse episódio, as discórdias políticas entre os setores envolvidos na revolução foram crescentes. Muito embora Távora sempre tivesse defendido a não participação de militares nos cargos da administração pública, acabou por substituir, gradativamente e na condição de delegado militar, cada civil por um militar em todas as interventorias do Norte e Nordeste, excetuando os territórios do Acre, Paraíba e Pernambuco. Nesse curto período em que ocupou o cargo de delegado, compreendeu que o papel histórico dos militares na organização do Brasil poderia ser mais amplo, e que o Estado era o lugar institucional onde poderiam aplicar a racionalidade de tudo o que haviam aprendido na sua formação profissional. 
Convidado em dezembro de 1932 por Vargas para assumir o Ministério da Agricultura, em substituição a Assis Brasil, resolveu aceitar a pasta com a premissa de poder colaborar com os governos do Nordeste em relação aos problemas das secas e poder influir nos trabalhos da Assembléia Constituinte. No período em que exerceu o cargo de ministro da Agricultura, o empenho de Távora em reestruturar as funções do Ministério foi o ponto que mais marcou o seu exercício. Foi esse empenho que gerou dois dos principais elementos do seu pensamento para a organização do Brasil: a racionalização administrativa e a ideia de um sindicalismo-cooperativista.

A julgar pelas suas Memórias, o Ministério encontrava-se "desorganizado e carente de profunda reforma estrutural e funcional" (TÁVORA, 1974, p. 92). Para corrigir a irracionalidade em que o Ministério se encontrava, seria necessário criar uma série de órgãos e diretorias competentes para as tarefas técnicas correspondentes às categorias do Ministério, agrupadas na agricultura, pecuária e recursos minerais. De imediato, o Ministério reestruturou-se com a criação de vários órgãos e autarquias, prática que era própria à gestão do novo Estado, buscando um funcionamento racional do aparelho público-administrativo.

Em conferência feita na ESG, em dezembro de 1951, com o título O Problema da racionalização administrativa no Brasil, Távora apresentou, pela primeira vez de maneira sistemática, as suas idéias para a organização político-administrativa do Brasil; julgava ser esse o problema preliminar do Brasil, de onde deveria partir a solução de todos os problemas possíveis. ${ }^{13}$ O texto dessa conferência reapareceu novamente na introdução de Organização, ligeiramente modificado, mas seguindo a mesma premissa da racionalização administrativa:

O Brasil tem, praticamente, por equacionar e resolver quase todos os seus problemas de base, inclusive, em primeiro plano, o problema preliminar da racionalização de sua estrutura político-administrativa. E parece-nos que, sem a solução prévia deste problema básico de organização, não será viável um equacionamento satisfatório de seus problemas políticos, econômicos e sociais, e, menos ainda, a realização metódica e eficiente das respectivas soluções. (TÁVORA, 1959, p. 5).

Sem a organização político-administrativa não seria viável garantir a segurança nacional e a convivência internacional. O problema seria, ainda, questão de disciplina mental das "elites" que "distanciada do terra-a-terra de tais realidades, perde-se, comumente, em devaneios fantasistas que vão, sem transição, do ufanismo ao derrotismo [...]" (TÁVORA, 1959, p. 6). [Itálicos do autor]). Nessa passagem, Távora faz referência, ainda, às críticas que Oliveira Vianna direcionava às nossas elites, que viam o Estado mais pelo viés espiritual do que material; e também a Alberto

13 Ver Juarez Távora (1952, p. 1). 
Torres, em sua crítica à adoção de sistemas políticos estranhos à natureza política, econômica e social brasileira.

No livro Organização para o Brasil, quando discute os mesmos elementos, o pensamento político autoritário procura se sofisticar: defende a instituição do sistema parlamentar de governo, com a mesma finalidade de harmonizar a ação dos poderes Legislativo e Executivo; propõe, também, a criação do quarto poder, o Poder Ordenador que, nos dizeres do próprio autor, seria uma espécie de cúpula do governo capaz de corrigir a ação dos demais poderes, na União, nos Estados e nos municípios, e, sobretudo, de coordenar as atividades político-administrativas dessas três esferas governamentais; e a federalização do Poder Judiciário e a sua libertação efetiva das tutelas dos executivos nacional e estadual, estendendo a sua jurisdição sobre as delegacias de polícia e os cartórios e registros públicos. (TÁVORA, 1959, p. 51-52).

\subsection{O sindicalismo-cooperativista e o cristianismo social}

Logo após Vargas ser eleito presidente constitucional, Távora deixou o Ministério da Agricultura, em julho de 1934. Com a experiência do ministério, e com base na publicação de um discurso que havia proferido na Assembleia, escreveu texto para conferência realizada na sede da Sociedade dos Amigos de Alberto Torres ${ }^{14}$, em novembro de 1935. O plano geral de organização e defesa de produção, à base sindical-cooperativa, adotado pelo Ministério da Agricultura ${ }^{15}$, publicado editorialmente apenas em 1957, compôs o terceiro capítulo de Produção para o Brasil. A conferência iniciava-se com a frase "O Brasil tem sido uma nação de atividade extensa e intensamente desorganizada. E é, como aliás seria natural, na ordem econômica onde mais se acentuam os prejuízos dessa desorganização generalizada." (TÁVORA, 1957, p. 103) A economia como campo de realização da produção foi objeto de grande preocupação de Távora. Em função dela, dedicou especial atenção à questão da extração de petróleo e de minérios no Brasil e à política de trabalho a ser adotada pelo Estado.

Após o período de envolvimento com o processo de desencadeamento da Revolução, e do esboço das linhas gerais do seu diagnóstico de desorganização do Brasil, possibilitado pelo contato direto com o ambiente público-administrativo, Juarez Távora voltou à atividade militar, da qual estivera afastado legalmente há mais de dez anos. Galgava o generalato com esse retorno, por meio do percurso institucional comum exigido na época. Em 1935, matriculou-se no Curso de

14 Criada em 1932, a Sociedade dos Amigos de Alberto Torres teve, como fundadores e participantes ilustres e das mais diversas áreas, os entusiastas da obra torreana Armando Magalhães Corrêa, Alberto Sampaio, Sabóia Lima, Alcides Gentil, Cândido Mota Filho, Oliveira Vianna, Juarez Távora e Ari Parreiras. Na agenda da instituição, que havia sido criada para "pensar o Brasil" à luz da obra de Alberto Torres, propunha-se, também, a luta contra o cangaço e contra o desmatamento. Ver CPDOC-FGV - JT dpf 1936.08.31

15 CPDOC-FGV - JT-21f 
Aperfeiçoamento de Arma de Engenharia, na Escola de Aperfeiçoamento de Oficiais (EsAO) na capital do País. (TÁVORA, 1974-1976, p. 132) Entrou para a Escola de Estado-Maior do Exército (EEM) no começo de 1936 e, em setembro do mesmo ano, recebeu a patente de tenente-coronel. Tendo ocupado cargos políticos de grande relevância durante o governo provisório - assim como outros oficiais "revolucionários" que também cursaram a EEM, como Osvaldo Cordeiro de Farias -, na Escola, Távora reforçou o pensamento quanto à "superioridade moral e o preparo técnico dos militares", de tal forma que as suas preocupações institucionais com os problemas brasileiros sedimentava "a crença no caráter natural e necessário do seu engajamento político". (SVARTMAN, 2006, p. 56).

O autor destaca em trecho que trata dos militares que cursaram a EEM naquele período, para um militar como Távora, que já havia traçado carreira política significativa, ter cursado a EEM àquela época permitiu acumular recursos (saberes, legitimidade e contatos) que "poderiam ser empregados tanto na carreira militar quanto na política, na medida em que as funções de estadomaior são, em essência, de planejamento e de administração da burocracia militar." (SVARTMAN, 2006, p. 11).

Távora escreveu o próximo texto a ser publicado somente no ano de 1937. A sua conferência Desvios da Economia Capitalista foi o trabalho em que traçou os seus primeiros estudos de economia e organização da produção no Brasil. A conferência, proferida na Sociedade Amigos de Alberto Torres, no Rio de Janeiro, não foi publicada imediatamente, nem no Brasil. Em 1943, por meio da Coleccion Problemas Americanos, dirigida por N. Freitas, foi publicada integralmente na Argentina com o título La organizacion econômica del Brasil. Posteriormente, a parte inicial do texto reapareceu no livro Produção, em 1957, com repetidas autocensuras de Távora em relação aos dados apresentados - mas, claramente, também em relação ao teor do texto, que poderia comprometê-lo passada a Segunda Guerra. O tom inicial era o da perplexidade:

Vivemos ainda entre as incertezas de uma época de transição. A humanidade tem defrontado, nestes últimos anos de sua história, difíceis encruzilhadas em todos os aspectos de sua atividade política, econômica e social. É, entretanto, no campo dos fatos econômicos que penetram mais profundamente as raízes da inquietação moderna [...]. Na verdade, o sistema econômico capitalista está marcado por graves irracionalidades funcionais e desvios éticos que desvirtuam suas eminentes fatalidades. Não há uma hierarquização orgânica que discipline logicamente a ação de seus fatores integrantes, nem um espírito de justiça social, informado na caridade cristã, capazes de reconduzir, dentro de cada grupo nacional, o homem à situação de sujeito, ao invés de simples objeto da atividade econômica, e de transformar em competição estimulante a atual tendência ao imperialismo monopolista de alguns Estados no concerto internacional. Os traços mais 
característicos dessa atividade econômica são, de um lado, o domínio político crescente do dinheiro, a serviço do egoísmo de poderosos grupos capitalistas, em detrimento do bem-estar social mínimo tolerável da enorme massa dos proletários, e, de outro lado, a riqueza pletórica de algumas nações, ora construída, ora mantida ou ampliada à custa da miséria centenária de outros povos. (TÁVORA, 1957, p. 14).

Por época de transição traduz-se, também, modernização. Távora compreendia já em 1937 que a questão da organização brasileira era principalmente problema de modernização e, portanto, de racionalização das esferas envolvidas na produção; o preocupava, assim, a forma com que essa racionalização deveria ser empreendida numa sociedade como a brasileira. A conferência, após essa introdução, em sua versão integral da publicação argentina, compõe uma série de considerações conceituais acerca da relação entre economia e seus "elementos fundamentais", que seriam a produção e o consumo, ligados pela circulação da riqueza. A produção resultaria dos fatores natureza, capital e trabalho, que analogicamente comporiam uma espécie de sistema de alavanca - a terra seria o ponto de apoio; o capital a alavanca e o trabalho a força aplicada. Para Távora, sem o fator de alavanca (capital), o problema da produção só poderia se resolver pelo simples aumento da força e da delonga, na obtenção dos resultados. Essa seria a realização do cooperativismo, por meio da união dos que trabalham. A circulação seria "fenômeno intermediário da cadeia econômica que consiste no truque por meio do qual as riquezas produzidas vão das mãos do produtor para as do consumidor". (TÁVORA, 1943, p. 12-14).

O problema da circulação consiste nas anomalias que envolvem o comércio, os transportes e as finanças. Távora diz que no mundo econômico moderno, os comerciantes impõem remuneração ínfima ao produtor e preços extorsivos ao consumidor; e que da mesma forma os transportes, como outro exemplo, a não ser em países que constituem monopólio de Estado, respondem como instrumento de lucro financeiro, antes de servirem à propulsão econômica; e, por fim, que a finança particular ou social, no mundo inteiro, por meio de seus líderes se sobrepõe à economia. (TÁVORA, 1943, p. 16).

Em termos práticos, o tema com o qual Távora se engajou para defender a sua visão "sistêmica" de economia foi o petróleo. Durante os debates de 1947, travou polêmica no Clube Militar com o general Júlio Caetano Horta a respeito da orientação a ser dada à política do petróleo. Se pouco mais de dez anos antes, como ministro da Agricultura, defendeu e criou os códigos de Minas e de Águas, incorporando as riquezas do subsolo ao patrimônio da União, dessa vez defendia incisivamente a opinião de que era necessário encarar o problema do petróleo tendo como premissa a "colaboração internacional", ou seja, reforçar a alavanca na economia brasileira. Para Távora, o novo estatuto deveria ter levado em conta os objetivos fundamentais da solução do problema petrolífero brasileiro àquela época, que dizia respeito às necessidades de consumo interno de petróleo e derivados, com preços adequados, o que reforçaria a capacidade econômico- 
financeira e a segurança nacional; e em segundo lugar, concorrer para a satisfação das necessidades continentais e, eventualmente, mundiais do petróleo. Dessa forma, só seria possível alcançar o $1^{\circ}$ objetivo se as possibilidades de extração fossem reforçadas pela cooperação continental. Tratava-se de caso de política internacional, orientada mesmo pelos Estados Maiores dos diversos países, e excluindo a possibilidade de monopólio estatal. (TÁVORA, 1955, p. 54-55).

O Brasil deveria entregar parte do controle da exploração do petróleo às empresas estrangeiras, pelo menos de início. O seu argumento se baseava, também, em termos de estratégia militar. Afirmava que a entrega da exploração do petróleo ao capital estrangeiro, que envolvia a adoção de tecnologia norte-americana, era ponto de garantia da segurança do continente contra a "ameaça comunista" e, no caso, elemento estratégico de preparação para a "guerra" cuja "ameaça aflige o mundo". (TÁVORA, 1955, p. 259-260).

No primeiro semestre de 1954 foi adotado o monopólio estatal sobre o petróleo e dado aumento de $100 \%$ para o salário-mínimo, o que contribuiu para o acirramento da crise política. Em meio aos acontecimentos, foi divulgado o texto Memorial dos Coronéis - o qual tinha Golbery como principal autor -, em que um grupo de coronéis e tenentes-coronéis se postava indignado com 0 governo federal e com as condições físicas e salariais do Exército. Em carta ao então Ministro da Guerra, general Zenóbio, Távora se mostrou preocupado com a repercussão do documento na imprensa, que estaria chamando a atenção do texto para uma alçada civil, da qual discordava e afirmava ser assunto apenas de interesse militar. ${ }^{16}$

A repercussão do manifesto, com as críticas de Lacerda aos atos do governo, acabou no atentado da Toneleros. Após várias discussões e reuniões dos militares e apuração do caso, que concluiu envolvimento da guarda presidencial, a Marinha e a Aeronáutica passaram a considerar necessária a renúncia do presidente da República. Preocupado, pois, com a unidade das Forças Armadas, Juarez Távora participou da redação do manifesto à nação, assinado por 30 generais, unindo as três armas na exigência do afastamento de Vargas do poder. Terminada a crise, Távora comprometeu-se a "nunca mais [se] envolver em tentativas de corrigir, recorrendo à força, os erros ou omissões de nossos governantes". (TÁVORA, 1974-1976, p. 254).

Nunca mais o fizera, de fato. Não diretamente, pois a sua contribuição já havia se concretizado ao fornecer algumas das principais bases da ideologia da ESG. Essa função de ideólogo ia se materializando no restante da sua vida pública e nas publicações que iam tomando corpo na Editora José Olympio, repositório das conferências na ESG e dos textos que elaborou em toda a sua carreira.

Mapeadas as anomalias da organização brasileira - enraizadas na irracionalidade das opções políticas da administração pública, e no desordenado desenvolvimento econômico -, Távora

16 Carta de Juarez Távora ao General Zenóbio do dia 14/05/1954. FGV-CPDOC - JT dpf 1952.09.06. Pasta "Juarez na ESG”. Seis dias depois, Juarez escreveu outra carta a Zenóbio, dizendo que se recusaria a receber o aumento concedido a todo o contingente, principalmente aos altos oficiais, pelas resoluções do Exército. 
direciona suas ideias para a distribuição de riqueza, ela mesma fator moral que solucionaria racionalmente os problemas da organização do Brasil. Nessa linha de preocupação, os textos de Juarez Távora apresentam a ideia de uma solução econômica e social que se assemelha ao nacional-socialismo, com concepção sindical-cooperativista para a produção. Esses elementos tomaram corpo na sua produção intelectual a partir do exemplo da sua atuação no Ministério da Agricultura.

Para Távora, o consumo seria o supremo objeto da economia, ao mesmo tempo em que é agente passivo da economia. Ao reconhecer em todas as pessoas o papel de consumidor e que, portanto, todos estão sujeitos à passividade do consumo, Távora considera que valem tanto as regras dos teóricos liberais, para o jogo da oferta e procura, quanto as dos marxistas, para a degradação em pobreza. Os consumidores, em meio à passividade do consumo, estariam relegados ao plano inferior no tratamento das discussões teóricas, e desamparados de proteção prática pelo poder público. A sua origem heterogênea, que os dissolvia na massa social, condenava-os à subalternização econômica. O poder de reação dos consumidores só poderia ser afirmado, então, por meio da organização ordenada e orientada hierarquicamente de cooperativas de consumo.

O sindicalismo-cooperativista, idéia que aparece a partir da conferência na Sociedade dos Amigos de Alberto Torres, em 1935, norteia a solução que dava para a questão da distribuição da riqueza, nos dizeres de proporcionar bem-estar e conforto à sociedade, e na prática com o objetivo definido de manter a ordem e evitar as insurreições sociais e demais oposições populares que pudessem comprometer seriamente o projeto de progresso organizado do Brasil. Sindicalismocooperativista seria, nesse sentido, "o sistema de mutualismo realizado dentro de vinculação harmônica entre o sindicato econômico-profissional e as cooperativas formadas pelos respectivos profissionais" e "a solidarização dos profissionais em cooperativas que se formam numa ordem racional de dependência - ligando-se todas pela origem, a uma organização central - o consórcio profissional-cooperativo". (TÁVORA, 1957, p. 7).

Seria, também, o "instrumento de defesa econômica dos consumidores-produtores", liberando a produção e o consumo da influência perturbadora do patrão, da usura financeira e do intermediário comerciante. (TÁVORA, 1943, p. 42). Távora remete a Pedro Toledo que, então ministro da Agricultura em 1911, adotou oficialmente a doutrina do sindicalismo-cooperativista, com a finalidade de "orientar as massas operárias de molde a salvaguardá-las da catequese anarquista, então em franca atividade". (TÁVORA, 1957, p. 110).

A doutrina, perdida após a saída de Pedro Toledo em 1913, teria sido retomada no seu Ministério da Agricultura durante o governo provisório da revolução de 1930. A idéia do cooperativismo, que até a conferência de 1935 dava ênfase apenas ao setor primário como forma de integrar relativamente o trabalhador rural nos lucros da produção, evoluiu para o que chamou na década de 1950 de empresa cooperativa. Em uma de suas conferências na ESG, em 1954, retoma a discussão no âmbito da guerra fria. A justiça distributiva, como denominou a questão da circulação 
de riqueza, era fundamental à segurança nacional. Para Távora, os termos do debate, naquele momento, deveriam considerar um campo intermediário entre as organizações capitalista e comunista:

\begin{abstract}
A paz do mundo atual é função de um equilíbrio bipolar de poder, entre o Ocidente democrático e o Oriente soviético. Esse equilíbrio de poder é instável, por falta de uma terceira força bastante poderosa para funcionar como fiel de balança entre aqueles dois pólos, cada um dos quais procura aliciar os elementos esparsos, ainda não polarizados, para ampliar e reforçar, de um lado, a chamada "cortina de ferro", que envolve o mundo comunista, e, de outro lado, estender e fechar o "cordão de cerco", que delineia a política de contenção das potências democráticas. [...] Não acredito na viabilidade de uma terceira posição política entre o grupo comunista oriental e o capitalismo do Ocidente. Mas julgo que é possível, no tocante a esse campo, ampliar e acelerar a política iniciada pela Grã-Bretanha, após a última guerra, de conceder autonomia progressiva aos povos coloniais; e, no que respeita ao duplo campo econômico-social, chegar-se a um meio termo razoável entre o capitalismo e o socialismo, conciliando, humanamente, o lado bom dos dois sistemas, sem incidir em seus defeitos. (TÁVORA, 1954, p. 1, 2).
\end{abstract}

Em 1959, no Organização para o Brasil, a questão já era vista como elemento do campo psicossocial da organização brasileira. Entre os diversos fatores a serem reformados, segundo Távora, mereceriam ser reorganizados os setores das relações de trabalho, no duplo sentido de: aperfeiçoar e ampliar a legislação que regula essas relações no que tange a direitos e deveres dos trabalhadores, e de estendê-la, como for viável, ao proletariado rural; conciliar, na empresa, os interesses do capital e do trabalho, pela participação deste na partilha dos lucros daquela, segundo os "preceitos da justiça distributiva cristã". (TÁVORA, 1959, p. 14).

Para Távora, essa organização do Brasil que deveria se distanciar da acepção mais liberal do capitalismo, assim como da solução socialista marxista, integrando a autoridade com a produção e a sociedade, só poderia realizar-se sob o signo do que chamou de organização pelo Cristianismo Social. Já na conferência de 1937, apontava para esse sentido, reproduzido em 1957 no Produção para o Brasil: 
controvérsias, e pertence, sem dúvida, ao terreno em que se ligam as questões propriamente econômicas com a questão social. A escola chamada liberal em seus diversos matizes, confinado a solução do problema à lei da oferta e da procura, tende a substituir a verdadeira democracia pela plutocracia, agravando cada vez mais a injustiça social. As escolas socialistas - especialmente as marxistas - para realizar sua sonhada justiça distributiva - "a cada um segundo suas necessidades, a cada um segundo sua capacidade ou segundo o trabalho realizado" - pretendem abolir total ou parcialmente a propriedade particular em favor da sociedade ou do Estado. $\mathrm{Na}$ prática, porém, não alcançariam solução razoável para o problema, substituindo apenas, politicamente, o patrão individual, múltiplo e fiscalizável, pelo patrão único e soberanamente tirânico - o Estado. (TÁVORA, 1957, p. 20-21).

E apresenta a noção de Cristianismo Social como "escola econômica" capaz de solucionar o problema da repartição de lucro:

Das escolas econômicas que se interpõem, como meio-termo, entre esses dois extremos, chamadas genericamente escolas evolucionistas, creio que é o cristianismo social visto em conjunto (escola católica e escola protestante) a mais capaz de conduzir o mundo, por uma rápida evolução pacífica, à prática da fraternidade econômica e da justiça social. Com efeito: O cristianismo social católico possui como instrumento de atuação econômica a "corporação" (sindicato vertical ou profissional) e tende a fundir entre si os interesses de empregados e de empregadores, substituindo a luta de classes pela fraternidade econômica dos agentes da produção. Ela, se não elimina, pelo menos humaniza o patrão. Por outro lado, o cristianismo social protestante possui como instrumento de atuação econômica a "cooperativa", e torna possível, pela união dos fracos, sua relativa libertação, - quer das imposições do capital, - quer das espoliações dos intermediários. Consegue deste modo neutralizar os prejuízos da usura e racionalizar a cadeia econômica subordinando os meios aos extremos cuja ligação opera. Conseqüentemente, o cristianismo social, em seu conjunto, é capaz de subtrair da cadeia econômica os motivos de maior prejuízo, procedentes do patrão, do capital e dos intermediários. (TÁVORA, 1957, p. 20-21). 
A idéia, simples na concepção e na aplicação, era de fato vincular a esfera econômica à moral religiosa. A solução - por mais espantosa que pareça - era-lhe a mais cabível e racional diante das "contradições do mundo capitalista" e das "ameaças do comunismo", tudo isso agravado pela percepção que desenvolveu da realidade nacional.

A mesma referência permanece nas conferências que realizou na ESG, só que integrada ao campo psicossocial. Em Organização para o Brasil, entendia o mesmo problema como questão fundamental de organização nacional, com a base do conceito de segurança nacional. O termo dá lugar ao correlato, torna-se a própria democracia cristã, integrando a Doutrina de Segurança Nacional:

O problema de nossa organização deve equacionar-se globalmente, em função da Segurança Nacional e em termos de uma verdadeira democracia cristã, isto é, não só política, mas também econômica e social. Comportará, conseqüentemente, um duplo sistema de equações simultâneas, para considerar, de um lado, o desenvolvimento harmônico das atividades políticoadministrativas (aí incluída sua componente militar), econômico-financeiras e psicossociais - como elementos integrantes do Poder Nacional; e, de outro lado, harmonizar a liberdade política com a ordem democrática, a liberdade econômica com o bem-estar social, e as garantias sociais com a plena eficiência do trabalho. [...] Ao psicossocial, como campo, que é, de aplicação das finalidades do Estado (aperfeiçoamento e bem-estar dos cidadãos e harmonização e progresso da sociedade) - tentando não só melhorar 0 padrão social do povo, como conciliar as franquias sociais com a plena eficiência do trabalho - de um lado, pelo justo equilíbrio de direitos e deveres do capital e do trabalho, expressos na legislação social e pela organização da empresa corporativa, com participação do trabalho nos seus lucros, e, de outro lado, pelo melhoramento do nível cultural e sanitário do trabalhador, em geral. (TÁVORA, 1959, p. 8-9).

O Cristianismo social encerrava, nele mesmo, o campo psicossocial. Somente por meio da moral cristã, baseada na justiça distributiva e cooperativa, é que o campo da produção poderia se organizar plenamente no Brasil. Tratava-se de operação metódica e racional. Organizar o Brasil significava racionalizar a administração pela reforma política, e desenvolver a economia com ênfase no setor agrário; sempre a serviço da harmonia e da ordem social que, mais do que progresso racionalmente positivo, deveria se firmar nos preceitos da moralidade cristã, única estrutura valorativa capaz de realizar o objetivo de dar segurança e desenvolvimento ao Brasil. 
Essa articulação entre sindicalismo-cooperativista, cristianismo social e racionalização administrativa atribui sentido ao pensamento de Juarez Távora. Formado ao longo de todo seu percurso político-ideológico, as ideias de Távora - pretensamente progressistas em termos de racionalização político-administrativa e de desenvolvimento econômico, ao mesmo tempo em que autoritárias e conservadoras nos termos de organização da produção voltada para a harmonia social - forneceram alguns dos principais elementos da base técnica e ideológica da perspectiva do desenvolvimento associado da DSN. Esse pensamento não representava tão somente o espírito organizacional do Exército: mais do que isso, já a partir do movimento de 1930, sob a experiência da prática interinstitucional, voltou-se aos elementos mais estruturais da organização produtiva do Brasil, como projeto de classe, que não era simplesmente a classe militar, mas uma classe que fosse ela mesma gestora do desenvolvimento econômico e da organização do estado brasileiro. Por fim, a tomada de poder definitiva dos militares em 1964 foi o momento em que Távora vislumbrou uma possibilidade efetiva de colocar o seu pensamento sobre a organização do estado, e da sociedade, em prática.

\section{Referências}

f

\section{Fontes documentais}

CPDOC-FGV - JT-21f.

CPDOC-FGV - JT dpf 1924.05.10.

CPDOC-FGV - JT dpf 1936.08.31.

CPDOC-FGV - JT dpf 1952.09.06.

\section{Bibliografia}

BORGES, Vavy Pacheco. Tenentismo e Revolução Brasileira. São Paulo: Brasiliense, 1992.

CARONE, Edgard. O Tenentismo. São Paulo: Difel, 1976. 
CARVALHO, José Murilo de. Forças Armadas e Política no Brasil. Rio de Janeiro: Jorge Zahar Editor, 2005.

FAUSTO, Boris. O movimento Tenentista em História do Século 20. São Paulo: Ed. Abril, 1975.

FORJAZ, Maria Cecília. Tenentismo e política: tenentismo e camadas médias urbanas na crise da Primeira República. Rio de Janeiro: Paz e Terra, 1977.

FORJAZ, Maria Cecília. Tenentismo e Aliança Liberal (1927-1930). São Paulo: Polis, 1978.

MALTA, Otávio. Os Tenentes na Revolução Brasileira. Rio de Janeiro: Civilização Brasileira, 1969.

SANTA ROSA, Virgínio. O sentido do tenentismo. 3. ed. São Paulo: Alfa-Omega, 1976. (original em 1933).

SCALÉRCIO, Márcio. O Exército Brasileiro e sua consolidação: 1934-1955. 1995. Dissertação (Mestrado em História) - Universidade Federal Fluminense, Niterói, 1995.

SILVA, Hélio. 1931: os Tenentes no Poder. Rio de Janeiro: Civilização Brasileira, 1967.

SILVA, Hélio. 1933 a Crise do Tenentismo. Rio de Janeiro: Civilização Brasileira, 1968.

SVARTMAN, Eduardo Munhoz. Guardiões da Nação: Formação profissional, experiências compartilhadas e engajamento político dos generais de 1964. 2006. Tese (Doutorado em Ciência Política) - Universidade Federal do Rio Grande do Sul, Porto Alegre, 2006.

TÁVORA, Juarez. À guisa de Depoimento sobre a Revolução Brasileira de 1924. São Paulo: Ed. O Combate, 1927. 1.v.

À Guisa de Depoimento sobre a Revolução Brasileira de 1924. Rio de Janeiro: Mendonça, Machado \& C., 1928. 3. v.

La organizacion econômica del Brasil. Buenos Aires: Coleccion Problemas Americanos dirigida por N. Freitas, 1943. v.11.

O problema da racionalização administrativa no Brasil. ESG: A-042-52, 1952.

Um ensaio de justiça distributiva. ESG: I-101-54, 1954.

Petróleo para o Brasil. Rio de Janeiro: Livraria José Olympio Editora, 1955.

Produção para o Brasil. 2. ed. Rio de Janeiro: Livraria José Olympio Editora, 1957.

Organização para o Brasil. Rio de Janeiro: Livraria José Olympio Editora,1959. 


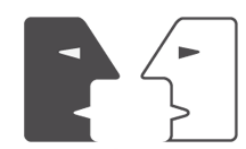

ANTÍTESES

Uma vida e muitas lutas. Memórias. Da planície à borda do altiplano. Rio de Janeiro: Biblioteca do Exército, Ed. e Livraria José Olympio, 1974. 1. v.

Uma vida e muitas lutas. Memórias. A caminhada no altiplano. Rio de Janeiro: Biblioteca do Exército, 1974-1976. 2. v.

Uma vida e muitas lutas. Memórias. Voltando à Planície. Rio de Janeiro: Biblioteca do Exército, 1977. 3. v.

TORRES, Alberto. O Problema Nacional Brasileiro: Introdução a um programa de organização nacional. 4. ed. São Paulo: Ed. Nacional, Ed. Universidade de Brasília, 1982.

TORRES, Alberto. Organização nacional. Rio de Janeiro: Imprensa Nacional, 1914. I pte.

Recebido em 28.02.2015 - aprovado em 19.10.2015 